\title{
PERBANDINGAN TUMPUAN JEPIT DAN SENDI PADA STRUKTUR POWER HOUSE DITINJAU DARI SEGI EFISIENSI MATERIAL DAN BIAYA (STUDI KASUS PROYEK PLTMG SERAM PEAKER)
}

\author{
(Comparison of Fixed And Pinned on Structures Power House is Reviewed from Material \\ Efficiency and Costs (Case Study of Peaker Seram PLTMG Project))
}

\author{
Ahmad Faoji ${ }^{1}$, Kusno Adi Sambowo ${ }^{2}$ \\ ${ }^{1}$ KSO PT Wijaya Karya PT Wika Rekayasa Konstruksi \\ ${ }^{2}$ Program Studi Teknik Sipil Universitas Pancasila \\ E-mail: faojiahmad2@gmail.com
}

\begin{abstract}
ABSTRAK
Seiring perkembangan zaman dan pola hidup manusia yang mempengaruhi kebutuhan akan bangunan gedung, perumahan dan juga kebutuhan pasokan listrik terutama di daerah yang terpencil, maka dari itu pemerintah memprogramkan 35.000 MW diseluruh Indonesia dari sabang sampai merauke dari mulai PLTU(Pembangkit Listrik Tenaga Uap) 25.58\%, PLTP (Pembangkit Listrik Tenaga Panas Bumi) 1.18\%, PLTG (Pembangkit Listrik Tenaga Gas) 26.12\% , PLTMG( Pembangkit Listrik Tenaga Mesin Gas )7.84\%, PLTGU ( Pembangkit Tenaga Gas Uap ) 40.68\% dan PLTM ( Pembangkit Listrik Tenaga Minihidro ) 0.59\%. Pada penelitian ini bertujuan untuk membuat perencanaan bangunan penunjang pada pembangkit listrik tenaga mesin gas yaitu banguana struktur power house dimana mengunakan aplikasi Staad pro untuk permodelannya dan Analisa gempa menggunakan puskim yang di tinjau dari segi efisiensi material dan biaya. Berdasarkan hasil analisis dari segi kedua tumpuan yang di bandingkan menggunakan permodelan staad pro dan peraturan pembebanan Indonesia tahun 1983 yang sudah dilakukan pada bangunan power house layak untuk dibagunun memenuhi dari gaya aksial, geser dan momen. Berdasarkan hasil analisis tersebut membandingkan tumpuan jepit dan sendi menghasilkan nilai rencana anggaran biaya untuk Jepit Rp.5.509.091.296,48 dan Sendi Rp. 6.369.147.621,76 jadi yang lebih Efisien adalah tumpuan Jepit.
\end{abstract}

Kata Kunci : Jepit, Sendi, Struktur power house, STAAD pro, Material, biaya

\begin{abstract}
Along with the development of the times and patterns of human life that affect the need for building, housing and electricity supply especially in remote areas, therefore the government has programmed 35,000 MW throughout Indonesia from Sabang to Merauke from 25.58\% Steam Power Plant (PLTP), PLTP (Geothermal Power Plant) 1.18\%, PLTG (Gas Power Plant) 26.12\%, PLTMG (Gas Engine Power Plant) 7.84\%, Steam Power Plant (PLTGU) 40.68\% and Minihidro Power Plant $0.59 \%$. In this study aims to make the planning of supporting buildings in the gas engine power plant is banguana powerhouse structure which uses Staad pro application for its modeling and seismic analysis using puskim in review in terms of material efficiency and cost. Based on the results of the analysis of the terms of the two pedestals are compared using the staad pro modeling and regulation of loading Indonesia in 1983 that has been done on building power house feasible to dibagunun meet from axial, shear and moment. Based on the results of these analyzes compare the staple of joints and joints to produce value plan budget cost for Rp.5.509.091.296,48 fixed and pinned Rp. 6,369,147,621,76 so the more Efficient is the fixed.
\end{abstract}

Keywords: Fixed, Pinned, Power house structure, STAAD pro, material, cost 


\section{PENDAHULUAN}

Seiring perkembangan zaman dan pola hidup manusia yang mempengaruhi kebutuhan akan bangunan gedung yang banyak digunakan sebagai perumahan, pusat perkantoran, perhotelan, tempat hiburan, pusat perbelanjaan, dan juga pemerintah memprogramkan 35.000 MW pemnagkit listrik diseluruh wilayah Indonesia dalam kurun waktu tahun dari (2015-2019) Program 35.000 MW ini bertujuan untuk memenuhi kebutuhan listrik masyarakat Indonesia dari Sabang sampai Merauke. Hal ini tentu akan berdampak signifikan bagi pertumbuhan ekonomi di luar Jawa, yang sebelumnya kekurangan suplai listrik. Dengan proyeksi pertumbuhan ekonomi 6-7\% pertahun. Penambahan listrik dalam negri membutuhkan tambahan sedikitnya 7.000 megawaat (MW) pertahun tertuang di RPLT (Rencana Penyediaan Tenaga Listrik)2015-2024. Dalam program 35.000 MW di bagi menjadi 2 pemerintah dan swasta. Dimana pemerintah mendapatkan 29\% (10.681 MW) dan swasta mendapatkan $79 \%$ ( $25.904 \mathrm{MW}$ ).dalam program ini pemerintah membagi ada beberapa pembangkit listrik yaitu : PLTU(Pembangkit Listrik Tenaga Uap) 25.58\%, PLTP (Pembangkit Listrik Tenaga Panas Bumi) 1.18\% , PLTG (Pembangkit Listrik Tenaga Gas) 26.12\% , PLTMG( Pembangkit Listrik Tenaga Mesin Gas )7.84\% , PLTGU ( Pembangkit Tenaga Gas Uap ) 40.68\% dan PLTM ( Pembangkit Listrik Tenaga Minihidro ) 0.59\%.

Proyek pembangunan Pembangkit listrik PLTMG Seram peaker ini sendiri terlatak di sebelah utara pulau ambon provinsi maluku,pulau seram terdiri dari 3 kabupaten, yaitu Kabupaten Maluku Tengah dengan ibukota Masohi serta dua kabupaten hasil pemekaran yaitu Kabupaten Seram Timur dengan ibu Kotanya Bula dan Kabupaten Seram Bagian Barat dengan Ibu Kotanya Piru.

\section{TUMPUAN SECARA UMUM}

Tumpuan merupakan tempat perletakan konstruksi untuk dukungan bagi konstruksi dalam meneruskan gaya-gaya yang bekerja menuju pondasi. Dalam ilmu mekanika rekayasa dikenal 3 jenis tumpuan yaitu tumpuan sendi, rol dan jepit. Sifat - sifat gaya reaksi yang timbul pada suatu benda yang mendapat beban tergantung bagaimana benda tersebut ditumpu atau bagaimana benda tersebut disambung dengan benda lain. Ada beberapa pengondisian tumpuan pada sebuah struktur.

\section{a. Tumpuan Rol}

Tumpuan rol adalah tumpuan yang dapat bergeser ke arah horizontal sehingga tumpuan ini tidak dapat menahan gaya horizontal. Pada tumpuan terdapat roda yang dapat begeser dimana berfungsi untuk mengakomodasi pemuaian pada konstruksi sehingga konstruksi tidak rusak. Tumpuan rol hanya mampu memberikan reaksi arah vertikal, artinya tumpuan hanya dapat menahan gaya vertikalnya saja, sehingga hanya terdapat 1 buah variabel yang akan diselesaikan (Rv saja).Jadi tumpuan Rol hanya mempunyai satu gaya reaksi yang tegak lurus dengan roll seperti pada gambar 2.1.

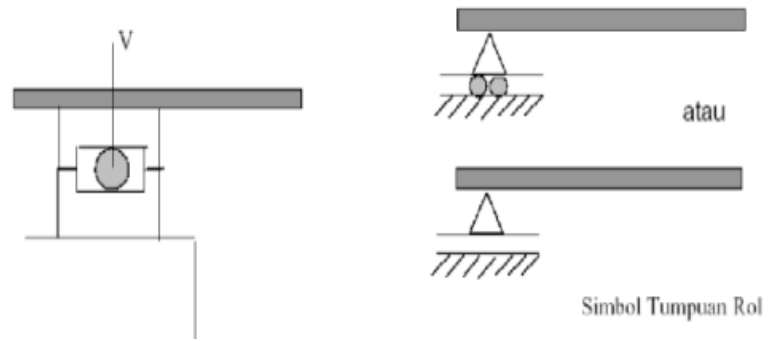

Gambar 1. Tumpuan Roll

\section{b. Tumpuan Sendi}

Tumpuan sendi sering disebut dengan engsel karena cara bekerja mirip dengan cara kerja engsel. Tumpuan sendi mampu memberikan reaksi arah vertikal dan horizontal, artinya tumpuan sendi dapat menahan gaya vertikal dan horizontal atau dengan kata lain terdapat 2 buah variabel yang akan diselesaikan ( $R v$ dan $R h$ ). Tumpuan sendi ini tidak dapat menahan momen.
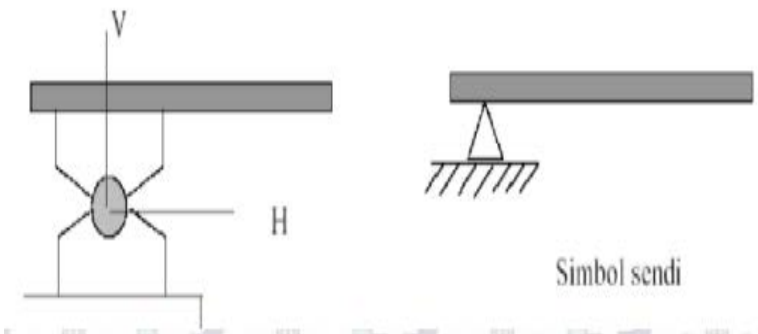

Gambar 2. Tumpuan Sendi

\section{c. Tumpuan Jepit}

Tumpuan jepit bisa dikonstruksikan seperti misalnya balok yang ditanam dalam tembokkan atau sebagai tumpuan pada balok terusan (jepitan elastis). Tumpuan jepit dapat memberikan reaksi atau tahan terhadap gaya horizontal, vertikal dan bahkan mampu memberikan reaksi terhadap putaran momen. Sehingga pada tumpuan jepit terdapat 3 buah variabel yang harus diselesaikan ( $R v$, Rh,dan $M$ ).Dengan demikian tumpuan jepit mempunyai tiga gaya reaksi sepertiyang terlihat pada gambar 3 .

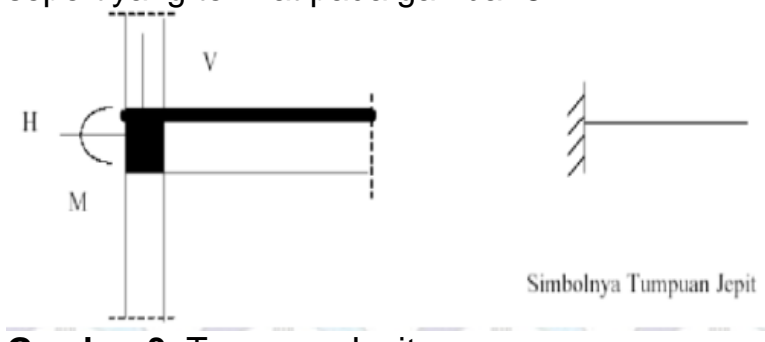

Gambar 3. Tumpuan Jepit

\section{PRINSIP DASAR PERANCANGAN}

Beberapa prinsip yang dapat memberikan arahan tentang perencana, denah, pondasi dan struktur bangunan gedung yang bisa diterapkan untuk masyarakat, agar bangunan yang akan dibangun dapat menahan getaran gempa bumi. Prinsipprinsipnya sebagai berikut:

1. Perencanaan gedung tahan gempa harus sederhana dan kompak. Struktur yang menerima beban dan bagian bangunan yang tidak 
menerima beban harus dianggap sebagai satu kesatuan yang saling mempengaruhi.

2. Gedung harus ringan. Makin berat sebuah gedung, makin besar daya massa jika terjadi gempa bumi. Makin tinggi gedung, harus makin ringan. Kontruksi atap yang berat dapat membahayakan struktur dibawahnya.

3. Struktur yang direncanakan harus sesederhana mungkin. Struktur yang sederhana akan tahan pada kondisi gempa bumi yang keras.

4. Denah sebaiknya direncanakan agar simetris, berbentuk segi empat sama sisi, atau lingkaran.

5. Tinggi gedung sebaik nya tidak melebihi empat kali lebar gedung.

6. Struktur gedung sebaiknya monolit, berarti seluruh struktur gedung dikonstruksikan dengan bahan yang sama karena pada saat gempa bumi bahan bangunan yang berbeda akan memberikan reaksi berbeda pula.

7. Ketebalan pelat lantai dan dimensi balok sebaiknya lebih besar dari pada biasanya utnuk menghindari getaran vertikal sejauh mungkin. Balok tidak boleh dibuat lebih lebar dari pada kolom agar tidak terjadi tegangan tambahan.

8. Ring balok horizontal pada setiap tingkat dengan batang tarik diagonal dapat meningkatkan kestabilan gedung.

9. Pondasi juga harus sesederhana dan sekuat mungkin sehingga tidak akan patah pada saat gempa. Sebainya dipilih pelat lantai beton bertulang atau pondasi lajur dengan sloof beton bertulang. Pondasi setempat sebaiknya dihindarkan.

10. Reaksi suatu gedung pada saat gempa bumi tergantung pada cara pembangunan dan bukan pada cara perencanaan. Maka, sangat pentinglah manajemen bangunan dan pengawasan saat pelaksanaan yang akan menjamin kualitas bangunan. Disamping itu, pemeliharaan dan perawatan bangunan dapat mempengaruhi kestabilan gedung saat gempa bumi.

11. Perubahan pada suatu gedung akibat pembangunan tambahan dan perubahan harus dilakukan secara cermat karena dapat mengubah kestabilan gedung terhadap gempa bumi.

\section{SISTEM STRUKTUR}

Didalam SNI 03-1726-2012 dijelaskan bahwa terdapat 6 macam sistem struktur, sistem struktur tersebut terdiri dari sebagai berikut :

1. Sistem dinding penumpu adalah sistem struktur yang tidak memiliki rangka ruang pemikul beban gravitasi secara lengkap, yang beban gravitasinya dipikul oleh dinding penumpu dan sistem bresing, sedangkan beban lateral akibat gaya gempa dipikul oleh dinding geser atau rangka bresing.

2. Sistem ganda adalah sistem struktur dengan rangka ruang pemikul beban gravitasi secara lengkap, sedangkan beban lateral yang diakibatkan oleh gempa dipikul oleh sistem rangka pemikul momen dan dinding geser ataupun oleh rangka pemikul momen dan rangka bresing.

3. Sistem interaksi dinding geser dan rangka adalah sistem struktur yang menggunakan kombinasi dinding geser dan sistem rangka beton bertulang biasa.

4. Sistem kolom kantilever adalah sistem struktur penahan gaya gempa, dimana gaya lateral yang diakibatkan oleh gempa disalurkan ke kolom yang berperilaku sebagai kolom kantilever yang terjepit di bagian dasar gedung.

5. Sistem rangka gedung adalah sistem struktur dengan rangka ruang pemikul beban gravitasi secara lengkap, sedangkan beban lateral yang diakibatkan oleh gempa dipikul dinding geser ataupun oleh rangka bresing.

6. Sistem rangka pemikul momen khusus adalah sistem struktur yang pada dasarnya memiliki rangka ruang pemikul beban gravitasi secara lengkap, sedangkan beban lateral yang diakibatkan oleh gempa dipikul oleh rangka pemikul momen melalui mekanisme lentur. Sistem ini terbagi menjadi 3, yaitu SRPMB (Sistem Rangka Pemikul Momen Biasa), SRPMM (Sistem Rangka Pemikul Momen Menengah), dan SRPMK (Sistem Rangka Pemikul Momen Khusus).

\section{JENIS PEMBEBANAN}

Beban yang akan ditanggung oleh suatu struktur tidak selalu dapat diramalkan seblumnya. Meski bebanbeban tersebut telah diketahui dengan baik pada salah satu lokasi struktur tertentu, distribusi dari elemen yang satu ke elemen yang lain pada keseluruhan struktur masih membutuhkan asumsi dan pendekatan. Jenis beban yang biasa digunakan dalam bangunan gedung meliputi :

\section{a) Beban Lateral yang terdiri dari : - Beban Gempa}

Beban gempa adalah salah satu beban yang harus diperhitungkan jika kita mendesain suatu bangunan di daerah yang rawan gempa. Tidak seperti beban-beban tipe lainnya dimana besarnya tidak dipengaruhi oleh struktur bangunan yang terkena gempa, besarnya beban gempa sangat dipengaruhi oleh kondisi struktur bangunannya. Ini terjadi karena beban gempa bekerja melalui lapisan tanah yang bergerak siklis baik dalam arah horisontal maupun vertikal.

Selain itu beban gempa juga dipengaruhi oleh kekakuan dari struktur bangunan. Jika kekakuan struktur dari bangunan itu sangat tinggi, maka bagian atas bangunan juga akan bergerak bersama-sama dengan bagian bawah, atau dengan kata lain periode dari struktur sama dengan periode dari gelombang gempa. Untuk bangunan bertingkat tinggi, strukturnya biasanya mempunya periode alaminya yang besar sehingga jika dikenai gelombang gempa yang berkepanjangan, akan terjadi kemungkinan terkena gempa dengan periode gelombang yang hampir sama dengan periode alami dari struktur. Jika hal ini terjadi maka akan terjadi resonansi yang akan mengakibat 
goncangan yang besar pada struktur. Dalam hal ini maka beban gempa yang terjadi $F>m \times$ a. Jadi dari uraian diatas kita bisa simpulkan faktor-faktor yang mempengaruhi beban gempa:

- Lokasi pusat gempa (jauh atau dekat)

- Kondisi tanah di lokasi bangunan yang ditinjau

- Karakteristik gempanya (intensitas, periodenya, lamanya)

\section{- Beban Angin}

Beban angin pada struktur terjadi karena adanya gesekan udara dengan permukaan struktur dan perbedaan tekanan dibagian depan dan belakang struktur. beban angin tidak memberi kontribusi yang besar terhadap struktur dibandingkan denganbeban yang lainnya. Menurut Schodek (1999), besarnya tekanan yang diakibatkan angin pada suatu titik akan bergantung pada kecepatan angin, rapat massa udara, lokasi yang ditinjau pada struktur, perilaku permukaan struktur bentuk geometris struktur, dimensi struktur.

\section{b) Beban Gravitasi yang terdiri dari : \\ - Beban Hidup}

Beban hidup adalah semua beban yang terjadi akibat penghunian atau penggunaan suatu gedung dan ke dalamnya termasuk beban-beban pada lantai yang berasal dari barang-barang yang dapat berpindah, mesin serta peralatan yang tidak merupakan bagian yang tak terpisahkan dari gedung dan dapat diganti selama masa hidup gedung tersbut, sehingga mengakibatkan perubahan pembebanan pada lantai dan atap. Beban hidup dapat menimbulakn lendutan pada struktur sehingga harus dipertimbangkan berdasarkan peraturan yang berlaku agar struktur tetap aman. Menurut Schueller (1998) beban yang disebabkan oleh isi benda-benda di dalam atau di atas suatu bngunan disebut beban penghunian (occupancy load). Beban ini mencakup beban peluang untuk berat manusia perabot partisi yang dapat dipindahkan, lemari besi buku lemari arsip perlengkapan mekanis dan sebagainya.

\section{- Beban mati}

Beban mati (DL) adalah berat dari semua bagian gedung yang bersifat tetap. Beban mati terdiri dari dua jenis, yaitu berat struktur itu sendiri dan superimpossed deadload (SiDL). Beban superimpossed adalah beban mati tambahan yang diletakkan pada struktur, dimana dapat berupa lantai (ubin/keramik), peralatan mekanik eletrikal, langit-langit dan sebagainya. Satuan material tersebut berdasarkan volume elemen. Berat satuan (unit weight) material secara empiris telah ditentukan dan telah banyak dicantumkan tabelnya pada sejumlah standar atau peraturan pembebanan.

\section{METODE}

Pengumpulan data dilakukan untuk memperoleh informasi yang dibutuhkan dalam rangka mencapai tujuan penelitian. Sebelum melakukan penelitian, seorang peneliti biasanya telah memiliki dugaan berdasarkan teori yang ia gunakan, dugaan tersebut disebut dengan hipotesis. Untuk membuktikan hipotesis secara empiris, seorang peneliti membutuhkan pengumpulan data untuk diteliti secara lebih mendalam.

Pengumpulan data dan informasi mengenai bangunan Power house mulai dari data umum sampai data teknis. Pengumpulan data dilakukan dengan 2 metode yaitu wawancara dan observasi. Data yang dapat digunakan adalah Desain Drawing Power House Data tersebut digunakan untuk pemodelan struktur dengan bentuk 3 dimensi oleh bantuan program bantu metode elemen hingga. Semua struktur di modelkan bentuk 3 dimensi untuk dianalisis lebih lanjut terkecuali model arsitekturalnya tidak dipermodelkan karena tidak mempengaruhi secara signifikan.

Tahap pelaksanaan penelitian dan penulisan yang dilakukan meliputi :

a. Melakukan studi literatur untuk mendapatkan tinjauan pustaka

b. Membuat model sistem pengumpulan data

c. Mengumpulkan data

d. Menganalisa data yang didapatkan

Proses penelitian perbandingan tumpuan jepit dan sendi dari segi material dan biaya bisa di lihat dibawah ini:

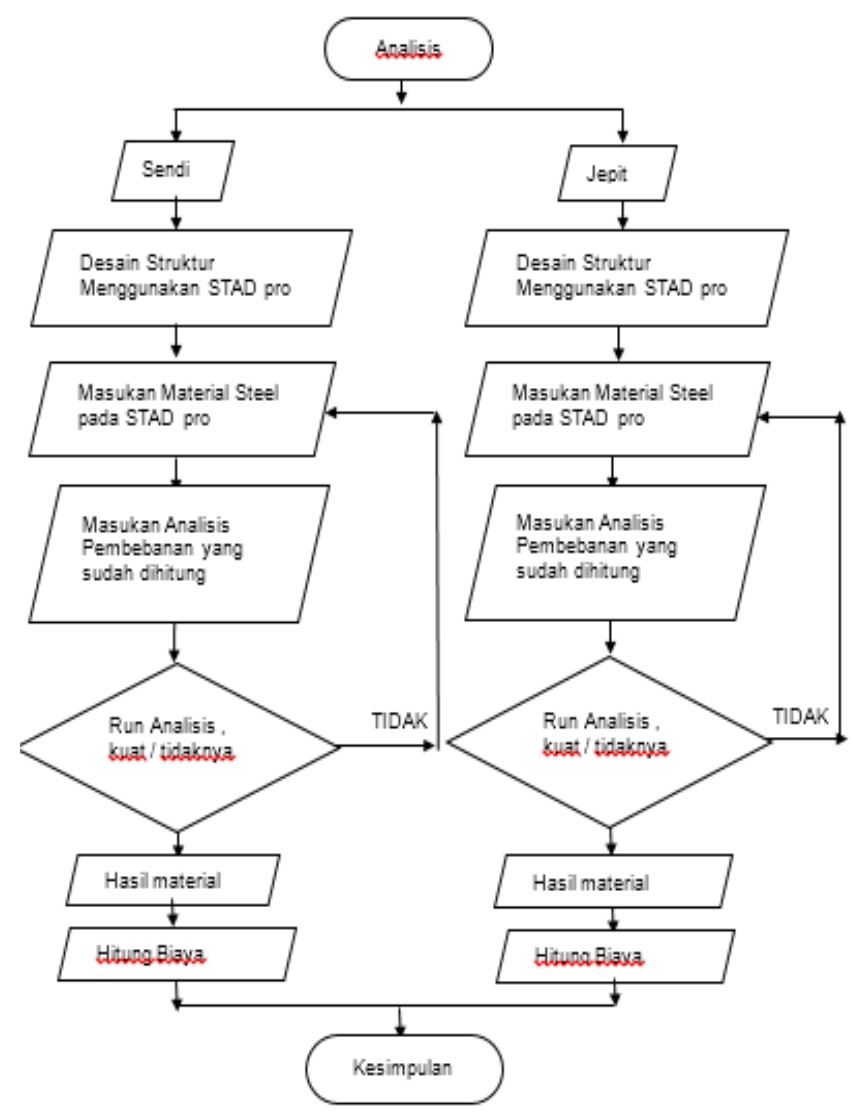




\section{PEMBAHASAN}

Permodelan Struktur Power House

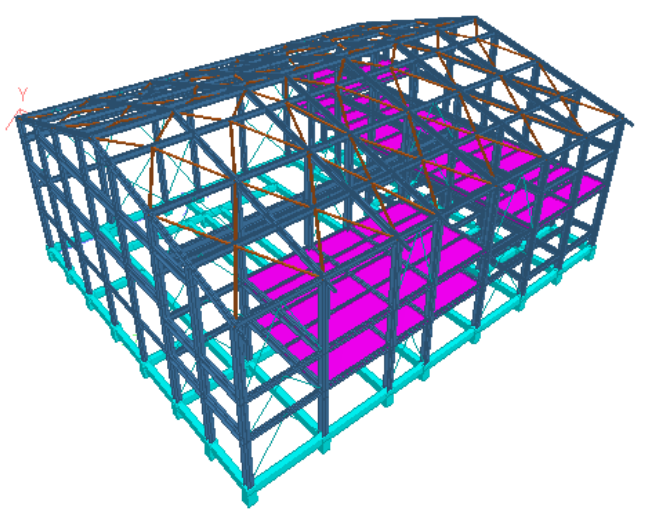

Gambar 4. Pemodelan Power House

Tabel 1 elevasi lantai

\begin{tabular}{|c|c|c|c|c|}
\hline No. & Lantai & $\begin{array}{c}\text { Elevasi } \\
\mathbf{( m )}\end{array}$ & $\begin{array}{c}\text { Selisih Tinggi } \\
\text { Floor To Floor } \\
\mathbf{( m )}\end{array}$ & $\begin{array}{c}\text { Luas } \\
\left(\mathbf{m}^{\mathbf{2}}\right)\end{array}$ \\
\hline 1 & Lantai 1 & +0.300 & - & $1.047,25$ \\
\hline 2 & Lantai 2 & $+6,550$ & 6,250 & 295 \\
\hline 3 & Lantai 3 & $+9,832$ & 3,282 & 80 \\
\hline
\end{tabular}

\section{SPESIFIKASI MATERIAL}

Sebelum mendapatkan material di bawah sebelumya di Staad pro melakukan percobaan dimensi material untuk jepit WF yang lebih kecil dari ukuran SC1 H300×300, SC2 H200×200, SB6 WF300×200, SB7

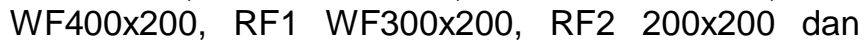
dinyatakan error atau tidak kuat jadi di ubahlah menjadi SC1 H350×350, SC2 H250×250, SB6 WF400x200, SB7 WF 600x200, RF1 WF400x200, RF2 WF300×200 dan dinyatakan aman.untuk sendi WF yang lebih kecil dari ukuran SC1 $\mathrm{H} 300 \times 300$, SC2 H200x200, SB6 WF300×200, SB7 WF400×200, RF1 WF300×200, RF2 200×200 dan dinyatakan error atau tidak kuat jadi di ubahlah menjadi SC1 H350×350, SC2 H250x250, SB6 WF400×200, SB7 WF 600×200, RF1 WF400×200, RF2 WF300 200 dinyatakan error di ubahlah menjadi SC1 H400x400, SC2 H300×300, SB6 WF500×200, SB7 WF 600×200, RF1 WF450×200, RF2 WF400×200 dan dinyatakan aman.Berikut Material yang di gunakan tumpuan jepit maupun sendi.

Tabel 2. Tumpuan Jepit

\begin{tabular}{|c|c|c|}
\hline No & Member & Profil \\
\hline 1 & COLUMN & H 350X350X13X19 \\
\hline 2 & COLUMN & H $250 \times 250 \times 9 \times 14$ \\
\hline 3 & BEAM & WF $200 \times 100 \times 5.5 \times 8$ \\
\hline 4 & BEAM & WF $300 \times 200 \times 8 \times 12$ \\
\hline 5 & BEAM & WF $400 \times 200 \times 8 \times 13$ \\
\hline
\end{tabular}

\begin{tabular}{|c|c|c|}
\hline No & Member & Profil \\
\hline 6 & BEAM & WF $600 \times 200 \times 11 \times 17$ \\
\hline 7 & BEAM & H $588 \times 300 \times 12 \times 20$ \\
\hline 8 & RAFTER & WF $400 \times 200 \times 8 \times 13$ \\
\hline 9 & RAFTER & WF $300 \times 200 \times 8 \times 12$ \\
\hline 10 & RAFTER & WF $150 \times 75 \times 5 \times 7$ \\
\hline 11 & BRACE & L 90X90X9 \\
\hline 12 & BRACE & T 200X200X8X13 \\
\hline 13 & BRACE & T 250X200X10X16 \\
\hline
\end{tabular}

Tabel 3Tumpuan Sendi

\begin{tabular}{|c|c|c|}
\hline NO & MEMBER & PROFILE \\
\hline 1 & COLUMN & H 400X400X13X21 \\
\hline 2 & COLUMN & H $300 \times 300 \times 10 \times 15$ \\
\hline 3 & BEAM & WF $200 \times 100 \times 5.5 \times 8$ \\
\hline 4 & BEAM & WF 400X200X8X13 \\
\hline 5 & BEAM & WF $500 \times 200 \times 10 \times 16$ \\
\hline 6 & BEAM & WF $600 \times 200 \times 11 \times 17$ \\
\hline 7 & BEAM & H 588X300X12X20 \\
\hline 8 & RAFTER & WF 450X200X9X14 \\
\hline 9 & RAFTER & WF 400X200X8X13 \\
\hline 10 & RAFTER & WF 150X75X5X7 \\
\hline 11 & BRACE & L $90 \times 90 \times 9$ \\
\hline 12 & BRACE & T 200X200X8X13 \\
\hline 13 & BRACE & T 250X200X10X16 \\
\hline
\end{tabular}

\section{MATERIAL PROPERTIS}

$\begin{array}{lll}\text { Kuat tekan beton } & : \mathrm{fc}^{\prime} & =30 \mathrm{MPa} \\ \begin{array}{l}\text { Hasil minimum stress } \\ \text { untuk bar }\end{array} & : \mathrm{fyd} & =4000 \mathrm{~kg} / \mathrm{cm}^{2} \\ \begin{array}{l}\text { Berat satuan beton } \\ \text { bertulang }\end{array} & : \gamma \mathrm{c} & =2400 \mathrm{~kg} / \mathrm{m}^{3} \\ \begin{array}{l}\text { Satuan berat tanah } \\ \text { Satuan berat air }\end{array} & : \gamma \mathrm{w} & =1400 \mathrm{~kg} / \mathrm{m}^{3} \\ \text { Berat satuan baja } & : \gamma s t e e l & =7850 \mathrm{~kg} / \mathrm{m}^{3} \\ \begin{array}{l}\text { Faktor keamanan } \\ \text { (safety factor) }\end{array} & & =2\end{array}$

\section{DIMENSI BANGUNAN}

Panjang Bangunan Lebar Bangunan Tinggi bangunan Tinggi bangunan total 


\section{PERHITUNGAN PEMBEBANAN}

\section{i. Beban Mati}

Berat bangunan dihitung secara otomatis oleh Staad Pro. Menggunakan fitur berat sendiri

Elemen atap

- Berat atap (Zincalum $0.7 \mathrm{~mm}$ ) $=20 \mathrm{Kg} / \mathrm{m}^{2}$

- Berat Purlin $(\mathrm{C} 150 \times 50 \times 20 \times 3.2)=6.8 \mathrm{Kg} / \mathrm{m}$

- Panjang kud-kuda

- Beban Purlin

$$
=16.3 \mathrm{~m}
$$$$
=8.53 \mathrm{Kg} / \mathrm{m}^{2}
$$

Total beban atap

$=$ berat atap + beban purlin

$=20 \mathrm{Kg} / \mathrm{m}^{2}+8.35 \mathrm{Kg} / \mathrm{m}^{2}$

$=28.35 \mathrm{Kg} / \mathrm{m}^{2}=29 \mathrm{Kg} / \mathrm{m}^{2}$

Berat Satuan Dinding Bata $\quad=250 \mathrm{Kg} / \mathrm{m}^{2}$

Plat lantai

Tebel plat lantai 1

Berat plat lantai

$$
=200 \mathrm{~mm}
$$

$=$ Berat beton $x$ tebel plat $x \mathrm{ME}$

$=2400 \times 200 \times 0.001=488$

$\mathrm{Kg} / \mathrm{m}^{2}$

$$
=4.88 \mathrm{kN} / \mathrm{m}^{2}
$$

Tebal plat lantai $2 \& 3=120 \mathrm{~mm}$

$$
\begin{aligned}
& =\text { Berat beton } \mathrm{x} \text { tebel plat } \times \mathrm{ME} \\
& =2400 \times 120 \times 0.001=288
\end{aligned}
$$

$\mathrm{Kg} / \mathrm{m}^{2}$

\section{ii. Beban hidup}

$$
=2.88 \mathrm{kN} / \mathrm{m}^{2}
$$

1. Beban hidup atap

$\mathrm{Lr}=100$

$\mathrm{Kg} / \mathrm{m}^{2}$

Pengurangan untuk beban hidup atap

$\mathrm{Lr}=\mathrm{Lo} \times \mathrm{R} 1 \times \mathrm{R} 2$

( ASCE 7-10)

Dimensi atap

Panjang banagnan $\quad=35.5 \mathrm{~m}$

Lebar atap $\quad=29.6 \mathrm{~m}$

Jumlah area

$=35.5 \mathrm{~m} \mathrm{x} 29.6 \mathrm{~m}=1050.8$ $\mathrm{m}^{2}$

Factor reduksi $\mathrm{R} 1=0.6 \quad($ ASCE $7-10)$

$\mathrm{F}=0.12 \times \tan \theta$

$=0.12 \times \tan 16$

$$
=3.441
$$

$\mathrm{Lr}=100 \times 0.6 \times 1 \quad=60 \mathrm{Kg} / \mathrm{m}^{2}$

Rain load R $\quad=20 \mathrm{Kg} / \mathrm{m}^{2}$

Rata2 beban hidup atap $=60 \mathrm{Kg} / \mathrm{m}^{2}$
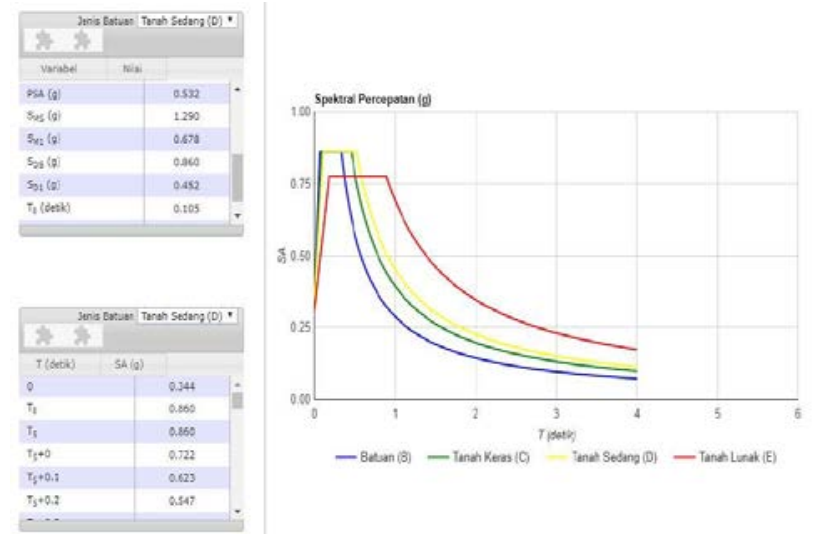

2. Beban hidup lantai

Lantai power house $\quad=100 \mathrm{~kg} / \mathrm{m}=1 \mathrm{kN} / \mathrm{m}$

\section{iii. Beban angin}

1. Data umum

- Kategori klasifikasi bangunan = III

- Kecepatan angin dasar, $\mathrm{V} \quad=28 \mathrm{x}$

$1.19=33.33$ ( from design basic )

$\mathrm{q}=\mathrm{V} / \mathrm{16}=33.33 / 16=69.4 \mathrm{Kg} / \mathrm{m}^{2}=70 \mathrm{Kg} / \mathrm{m}^{2}$

- $\quad$ Tipe bangunan

Building struktur

2. Data bangunan utama

- $\quad$ Tinggi building, $\mathrm{T} \quad=16.6$

$\mathrm{m}$

Panjang bangunan, $\mathrm{P} \quad=35.5$

$\mathrm{m}$

Lebar bangunan ,L

$\mathrm{m}$

3. Beban angin dari arah $X \& Z$ bangunan

$$
\begin{array}{rlrl}
\text { Sisi kolom } & =q \times \text { Lebar } \times 0.9 \\
-\quad \text { Tengah } & =70 \mathrm{Kg} / \mathrm{m}^{2} \times 29.6 \mathrm{~m} \times 0.9 \\
& =1864.8 \mathrm{Kg} / \mathrm{m}^{2}=>18.64 \\
\mathrm{kN} / \mathrm{m}^{2} & & \\
\text { - Tepi } & =70 \mathrm{Kg} / \mathrm{m}^{2} \times 14.8 \mathrm{~m} \times 0.9 \\
& =932.4 \mathrm{Kg} / \mathrm{m}^{2}=>9.32 \mathrm{kN} / \mathrm{m}^{2} \\
\text { Sisi atap } & =q \times \mathrm{Lebar} \times 0.4 \\
\text { - Tengah } & =70 \mathrm{Kg} / \mathrm{m}^{2} \times 29.6 \mathrm{~m} \times 0.4 \\
-\quad \text { Tepi } & =828.8 \mathrm{Kg} / \mathrm{m}^{2}=>8.28 \mathrm{kN} / \mathrm{m}^{2} \\
& =70 \mathrm{Kg} / \mathrm{m}^{2} \times 14.8 \mathrm{~m} \times 0.4 \\
& =414.4 \mathrm{Kg} / \mathrm{m}^{2}=>4.14 \mathrm{kN} / \mathrm{m}
\end{array}
$$

\section{iv. Beban Gempa}

Design respon spectra mengkuti SNI-03-1726-2012

$$
\begin{array}{ll}
\text { Tanah dasar } & \text { : Tanah lunak Kelas D wilayah } \\
& \text { gempa zona } 5
\end{array}
$$

Kategori Resiko Bangunan: Kategori resiko II

$$
\begin{aligned}
& \mathrm{Fa}= 1 \mathrm{~g} \\
& \mathrm{Ss}= 1.29 \mathrm{~g} \\
& \mathrm{Fv}= 1.567 \mathrm{~g} \\
& \mathrm{~S} 1= 0.433 \mathrm{~g} \\
& \mathrm{SMS}= \mathrm{Fa} \times \mathrm{Ss}=1.290 \\
& \mathrm{SM} 1=\mathrm{Fv} \times \mathrm{S} 1=0.679 \\
& \mathrm{Sa}=\mathrm{SDS} \times(0.4+0.6 \mathrm{Tf} / \mathrm{TO} \\
& \mathrm{Sa}=\mathrm{SD} 1 / \mathrm{Tf} \\
& \mathrm{SDS}= 0.860 \\
& \mathrm{SD} 1= 0.452 \\
& \mathrm{~T} 0= 0.2 \mathrm{SD} 1 / \mathrm{SDS}=0.2 \times 0.452 / 0.860=0.105 \\
& \text { detik } \quad=0.452 / 0.860=0.256 \text { detik }
\end{aligned}
$$




\section{Beam And Force}

Tabel 4. Beam And Force Jepit

\begin{tabular}{|l|r|l|r|r|r|r|r|r|r|}
\hline & Beam & L/C & Node & Fx kN & Fy kN & Fz kN & Mx kN-m & My kN-m & Mz kN-m \\
\hline Max Fx & 259 & $381,2 \mathrm{DL}+1$ & 250 & 1944.2 & 1.37 & 0.565 & 0.004 & -2.006 & 1.81 \\
\hline Min Fx & 10 & 39 0,9 DL +1 & 17 & -334.7 & 1.17 & 0 & 0 & 0 & 0 \\
\hline Max Fy & 45 & $381,2 \mathrm{DL}+1$ & 55 & 0 & 470.458 & 0 & 0 & 0 & 451.727 \\
\hline Min Fy & 457 & $381,2 \mathrm{DL}+1$ & 58 & 0 & -456.591 & -0.001 & 0 & 0 & 437.86 \\
\hline Max Fz & 542 & $371,2 \mathrm{DL}+1$ & 225 & 86.104 & -10.393 & 344.2 & -0.064 & -5.565 & -37.596 \\
\hline Min Fz & 582 & $371,2 \mathrm{DL}+1$ & 183 & 36.406 & 5.735 & -572.2 & 0.28 & 381.567 & 0.532 \\
\hline Max Mx & 1512 & $371,2 \mathrm{DL}+1$ & 216 & 213 & -60.457 & -61.8 & 60.322 & -1.646 & -35.019 \\
\hline Min Mx & 1397 & $371,2 \mathrm{DL}+1$ & 628 & 198.82 & 5.735 & 158 & -24.867 & -58.369 & 17.252 \\
\hline Max My & 223 & $371,2 \mathrm{DL}+1$ & 220 & 106.15 & -5.882 & -397.4 & 9.881 & 1377.658 & -26.532 \\
\hline Min My & 237 & $371,2 \mathrm{DL}+1$ & 219 & 67.179 & -1.956 & 104.3 & -0.013 & -1560.05 & -8.09 \\
\hline Max Mz & 1230 & $381,2 \mathrm{DL}+1$ & 542 & 0 & -295.886 & 0 & 0 & -0.001 & 471.582 \\
\hline Min Mz & 571 & $381,2 \mathrm{DL}+1$ & 305 & 47.989 & 91.909 & 0.289 & 0.006 & 0.247 & -527.421 \\
\hline
\end{tabular}

Tabel 5. Beam And Force Sendi

\begin{tabular}{|l|r|l|r|r|r|r|r|r|r|}
\hline & Beam & L/C & Node & Fx kN & Fy kN & Fz kN & Mx kip-in & My kip-in & Mz kip-in \\
\hline Max Fx & 259 & $351,2 \mathrm{DL}+1$, & 250 & 1113.9 & 0 & 0 & 0 & 0 & 0 \\
\hline Min Fx & 10 & $371,2 \mathrm{DL}+1$ & 17 & -330.5 & 1.561 & 0 & 0.002 & 0 & 0 \\
\hline Max Fy & 45 & $351,2 \mathrm{DL}+1$, & 55 & 0 & 300.198 & -0.001 & 0 & 0.006 & 2548.234 \\
\hline Min Fy & 457 & $361,2 \mathrm{DL}+1$, & 58 & 0 & -313.681 & 0.022 & 0 & 0.065 & 2667.562 \\
\hline Max Fz & 542 & $371,2 \mathrm{DL}+1$ & 225 & 101.27 & -14.648 & 344.4 & -0.567 & -81.936 & -394.478 \\
\hline Min Fz & 582 & $371,2 \mathrm{DL}+1$ & 183 & 35.308 & 9.51 & -568.9 & -18.365 & 3294.908 & 20.683 \\
\hline Max Mx & 1512 & $371,2 \mathrm{DL}+1$ & 216 & 203.31 & -64.714 & -69.06 & 788.443 & 52.026 & -311.776 \\
\hline Min Mx & 1397 & $371,2 \mathrm{DL}+1$ & 628 & 190.06 & 9.51 & 152.7 & -310.96 & -527.118 & 245.791 \\
\hline Max My & 223 & $371,2 \mathrm{DL}+1$ & 220 & 123.02 & -7.402 & -395.2 & 84.745 & 12173.63 & -283.789 \\
\hline Min My & 237 & $371,2 \mathrm{DL}+1$ & 219 & 76.179 & -2.645 & 104.3 & -0.043 & -13624.9 & -80.954 \\
\hline Max Mz & 1534 & $371,2 \mathrm{DL}+1$ & 128 & 29.269 & -5.975 & -0.026 & -6.53 & -1.356 & 4177.796 \\
\hline Min Mz & 571 & $351,2 \mathrm{DL}+1$, & 305 & 34.113 & 69.333 & 0.041 & 0.041 & 0.388 & -2985.97 \\
\hline
\end{tabular}

\section{Displacement}

Tabel 6.Displacement Jepit

\begin{tabular}{|c|c|c|c|c|c|c|c|c|c|}
\hline & & & Horizontal & Vertical & Horizontal & \begin{tabular}{|l|} 
Resultant \\
\end{tabular} & Rotational & & \\
\hline & Node & $L / C$ & $\mathrm{Xmm}$ & $\mathrm{Y} \mathrm{mm}$ & $Z \mathrm{~mm}$ & $\mathrm{~mm}$ & rX rad & rY rad & $\mathrm{rZ} \mathrm{rad}$ \\
\hline $\operatorname{Max} X$ & 21 & $8371,2 \mathrm{DL}+1,3 \mathrm{WL}$ & 622.257 & -0.008 & 1.234 & 3622.258 & 0 & -0.167 & 0.001 \\
\hline $\operatorname{Min} X$ & 21 & $2371,2 \mathrm{DL}+1,3 \mathrm{WL}$ & -40.004 & -0.893 & 0.853 & 40.023 & 0 & 0.003 & -0.003 \\
\hline $\operatorname{Max} Y$ & 19 & $0390,9 \mathrm{DL}+1 \mathrm{WL}$ & 0.564 & 83.7 & -11.265 & 84.457 & 0 & 0 & ) \\
\hline $\operatorname{Min} Y$ & 19 & $1381,2 \mathrm{DL}+1 \mathrm{E}+\mathrm{LL}$ & 0.885 & \begin{tabular}{|l|}
-119.244 \\
\end{tabular} & 14.946 & 120.18 & 0.002 & 0 & 0 \\
\hline Max Z & 12 & $8371,2 \mathrm{DL}+1,3 \mathrm{WL}$ & 0.289 & -0.158 & 79.537 & 79.538 & 0.001 & 0.023 & 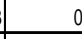 \\
\hline $\operatorname{Min} Z$ & 12 & $9381,2 \mathrm{DL}+1 \mathrm{E}+\mathrm{LL}$ & 0.33 & -0.618 & -48.088 & 48.093 & -0.004 & 0.007 & 0 \\
\hline Max rX & 48 & $5381,2 \mathrm{DL}+1 \mathrm{E}+\mathrm{LL}$ & 0.61 & -74.849 & 2.546 & 74.895 & 0.018 & 0 & 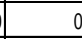 \\
\hline Min rX & 70 & $9371,2 \mathrm{DL}+1,3 \mathrm{WL}$ & -0.218 & -16.737 & 16.358 & 23.404 & -0.017 & 0.001 & 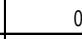 \\
\hline Max ry & 62 & $5371,2 \mathrm{DL}+1,3 \mathrm{WL}$ & 11.163 & -0.126 & 1.45 & 11.257 & 0 & 0.597 & 0 \\
\hline Min rY & 62 & $8371,2 \mathrm{DL}+1,3 \mathrm{WL}$ & 2.399 & -0.097 & 1.08 & 2.633 & 0 & -0.512 & 0.001 \\
\hline Max rZ & 22 & $3371,2 \mathrm{DL}+1,3 \mathrm{WL}$ & 1327.312 & -0.289 & 1.034 & 1327.312 & 0 & 0.157 & 0.577 \\
\hline Min rZ & 66 & $9371,2 \mathrm{DL}+1,3 \mathrm{WL}$ & 1813.967 & -0.03 & 0.775 & 1813.968 & 0 & -0.079 & -0.456 \\
\hline Max Rst & 21 & $8371,2 \mathrm{DL}+1,3 \mathrm{WL}$ & 3622.257 & -0.008 & 1.234 & 3622.258 & 0 & -0.167 & 0.001 \\
\hline
\end{tabular}

Tabel 7. Displacement Sendi

\begin{tabular}{|c|c|c|c|c|c|c|c|c|c|}
\hline & & & Horizonta & Vertical & Horizonta & Resultant & Rotationa & & \\
\hline & Node & $L / C$ & $\mathrm{Xmm}$ & $Y \mathrm{~mm}$ & $\mathrm{Zmm}$ & $\mathrm{mm}$ & rX rad & rY rad & $\mathrm{rZ} \mathrm{rad}$ \\
\hline $\operatorname{Max} X$ & 218 & $371,2 \mathrm{DL}+1,3 \mathrm{~W}$ & 549.005 & 0.053 & 0.942 & 3549.01 & 0 & -0.165 & 0 \\
\hline $\operatorname{Min} X$ & 212 & $371,2 \mathrm{DL}+1,3 \mathrm{~W}$ & -24.711 & -0.621 & 0.635 & 24.727 & 0 & 0.002 & -0.002 \\
\hline $\operatorname{Max} Y$ & 190 & $371,2 \mathrm{DL}+1,3 \mathrm{~W}$ & 0.66 & 79.05 & \begin{tabular}{|l|}
-10.103 \\
\end{tabular} & 79.696 & -0.001 & 0 & 0 \\
\hline $\operatorname{Min} Y$ & 190 & $351,2 \mathrm{DL}+1,6 \mathrm{LL}$ & 0.136 & -38.921 & 4.743 & 39.209 & 0.001 & 0 & 0 \\
\hline $\operatorname{Max} Z$ & 128 & $371,2 \mathrm{DL}+1,3 \mathrm{~W}$ & 0.309 & -0.091 & 60.076 & 60.077 & 0.001 & 0.021 & 0 \\
\hline $\operatorname{Min} Z$ & 292 & $371,2 \mathrm{DL}+1,3 \mathrm{~W}$ & 0.434 & -0.388 & -18.933 & 18.942 & -0.001 & 0 & 0 \\
\hline Max rX & 17 & $371,2 \mathrm{DL}+1,3 \mathrm{~W}$ & 0.198 & 38.166 & 1.698 & 38.205 & 0.008 & 0 & 0 \\
\hline Min rX & 709 & $371,2 \mathrm{DL}+1,3 \mathrm{~W}$ & -0.47 & -13.623 & 16.506 & 21.407 & -0.014 & 0.001 & 0 \\
\hline MaxrY & 625 & $371,2 \mathrm{DL}+1,3 \mathrm{~W}$ & 7.609 & -0.081 & 1.187 & 7.701 & 0 & 0.585 & 0 \\
\hline \begin{tabular}{|l|} 
Min rY \\
\end{tabular} & 628 & $371,2 \mathrm{DL}+1,3 \mathrm{~W}$ & 2.859 & -0.057 & 0.769 & 2.961 & 0 & -0.496 & 0 \\
\hline Max rZ & 223 & $371,2 \mathrm{DL}+1,3 \mathrm{~W}$ & 1302.57 & -0.251 & 0.667 & 1302.57 & 0 & 0.154 & 0.566 \\
\hline Min rZ & 669 & $371,2 \mathrm{DL}+1,3 \mathrm{~W}$ & 1779.17 & 0.007 & 0.561 & 1779.17 & 0 & -0.079 & -0.446 \\
\hline Max Rst & 218 & $371,2 \mathrm{DL}+1,3 \mathrm{~W}$ & 3549.01 & 0.053 & 0.942 & 3549.01 & 0 & -0.165 & 0 \\
\hline
\end{tabular}

RENCANA ANGGARAN BIAYA

Tabel 8. Tumpuan Jepit

\begin{tabular}{|c|c|c|c|c|c|r|r|r|}
\hline \multicolumn{7}{|c|}{ POWER HOUSE STEEL STRUCTURE } \\
\hline
\end{tabular}

RENCANA ANGGARAN BIAYA

Tabel 9. Tumpuan Sendi

\begin{tabular}{|c|c|c|c|c|c|c|c|c|}
\hline \multicolumn{9}{|c|}{ POWER HOUSE STEEL STRUCTURE } \\
\hline \multicolumn{9}{|c|}{ PLTMG SERAM PEAKER 20 MW ( Tumpuan Sendi ) } \\
\hline \multirow{2}{*}{ NO } & \multirow{2}{*}{ MEMBER } & \multirow{2}{*}{ PROFILE } & \multirow{2}{*}{\begin{tabular}{|c|} 
WEIGHT \\
$\mathrm{KG} / \mathrm{M}$ \\
\end{tabular}} & \multicolumn{2}{|c|}{ TOTAL LENGT } & \multicolumn{2}{|c|}{ TOTAL WEIGHTH harga (Satuar) } & \multirow{2}{*}{$\begin{array}{c}\text { Total (harga) } \\
\mathrm{Rp}\end{array}$} \\
\hline & & & & QTY & M & KG & $\mathrm{Rp}$ & \\
\hline 1 & COLUMN & H $400 \times 400 \times 13 \times 21$ & 172 & 47 & 567.371 & $97,587.81$ & $17,800.00$ & $1,737,063,053.60$ \\
\hline 2 & COLUMN & H 300X300X10X15 & 94 & 4 & 58.381 & $5,487.81$ & $17,800.00$ & $97,683,089.20$ \\
\hline 3 & BEAM & WF $200 \times 100 \times 5.5$ & 21.3 & 4 & 16.64 & 354.43 & $18,300.00$ & $6,486,105.60$ \\
\hline 4 & BEAM & WF 400X200x8x1 & 66 & 162 & 1608.66 & $106,171.56$ & $18,300.00$ & $1,942,939,548.00$ \\
\hline 5 & BEAM & WF 500X200x10X & 89.6 & 56 & 273.3 & $24,487.68$ & $18,300.00$ & $448,124,544.00$ \\
\hline 6 & BEAM & WF $600 \times 200 \times 11 \times$ & 106 & 56 & 205.2 & $21,751.20$ & $18,300.00$ & $398,046,960.00$ \\
\hline 7 & BEAM & H $588 \times 300 \times 12 \times 2 \mathrm{~d}$ & 151 & 38 & 222.1 & $33,537.10$ & $17,800.00$ & $596,960,380.00$ \\
\hline 8 & RAFTER & WF 450X200X9×1 & 76 & 64 & 236.8 & $17,996.80$ & $18,300.00$ & $329,341,440.00$ \\
\hline 9 & RAFTER & WF $400 \times 200 \times 8 \times 1$ & 66 & 49 & 248.5 & $16,401.00$ & $18,300.00$ & $300,138,300.00$ \\
\hline 10 & RAFTER & WF $150 \times 75 \times 5 \times 7$ & 14 & 16 & 16 & 224.00 & $18,300.00$ & $4,099,200.00$ \\
\hline 11 & BRACE & L 90X90X9 & 33 & 82 & 487.264 & $16,079.71$ & $16,000.00$ & $257,275,392.00$ \\
\hline 12 & BRACE & T 200X200×8X13 & 33 & 76 & 342.3 & $11,295.90$ & $18,300.00$ & $206,714,970.00$ \\
\hline 13 & BRACE & T 250X200X10X16 & 44.8 & 12 & 54.004 & $2,419.38$ & $18,300.00$ & $44,274,639.36$ \\
\hline & & & & & Total & $353,794.39$ & & $6,369,147,621.76$ \\
\hline
\end{tabular}

\section{KESIMPULAN}

Berdasarkan hasil Perbangdingan struktur Gedung Power House Jepit dan Sendi , maka dapat diambil kesimpulan sebgai berikut :

1. Berdasarkan analisis perencanaan desain menggunakan Staad pro perencanaan Gedung Power House tersebut dinyatakan aman dari segi tumpuan jepit dan sendi.

2. Berdasarkan hasil analisis tersebut membandingkan tumpuan jepit dan sendi menghasilkan nilai rencana anggaran biaya untuk Jepit Rp.5.509.091.296,48 dan Sendi Rp. 6.369.147.621,76 jadi yang lebih Efisien adalah tumpuan Jepit.

3. Berdasarkan analisis material yang digunakan adalah jepit sebagai berikut : 


\begin{tabular}{|l|l|}
\hline COLUMN & H $350 \times 350 \times 13 \times 19$ \\
\hline COLUMN & H $250 \times 250 \times 9 \times 14$ \\
\hline BEAM & WF $200 \times 100 \times 5.5 \times 8$ \\
\hline BEAM & WF $300 \times 200 \times 8 \times 12$ \\
\hline BEAM & WF $400 \times 200 \times 8 \times 13$ \\
\hline BEAM & WF $600 \times 200 \times 11 \times 17$ \\
\hline BEAM & H $588 \times 300 \times 12 \times 20$ \\
\hline RAFTER & WF $400 \times 200 \times 8 \times 13$ \\
\hline RAFTER & WF $300 \times 200 \times 8 \times 12$ \\
\hline RAFTER & WF $150 \times 75 \times 5 \times 7$ \\
\hline BRACE & L $90 \times 90 \times 9$ \\
\hline BRACE & T $200 \times 200 \times 8 \times 13$ \\
\hline BRACE & T $250 \times 200 \times 10 \times 16$ \\
\hline
\end{tabular}

\section{UCAPAN TERIMA KASIH}

Pertama saya ucapkan terima kasih kepadakedua orang tua saya yang selalu mendoakan dan mensuport saya dari awal kuliah sampai sekarang, kedua saya terima kasih kepada pak kusno adi sambowo selaku pembimbing saya yang membantu menyelesaikan tugas akhir ini, ketiga teima kasih kepada kuta jurusan pak akhmad dofir, sekertaris jurusan ibu niken warastuti dan dosen-dosen yang lain telah mengajarkan dan membagikan ilmunya kepada saya, yang ke 4 terima kasih kepada pak dewanto dan ibu siska yang memberi data untuk tugas akhir saya, dan yang terakhir terima kasih kepada temen-temen saya yang telah medoakan dan mensuport saya dari belakang terutama team Hasemeleh Uni-uni Padang Dinni, Mila dan Ledy, dan abang-abang ku Bang roni dan Yonky.

\section{REFERENSI}

Anonim. (2012). Tata Cara Perencanaan Ketahanan Gempa Untuk Struktur Bangunan Gedung dan Non Gedung, SNI 03-1726-2012, BSN, Bandung.

Anonim. (1983) Peraturan Pembebanan Indonesia Gedung 1983, Direktorat Penyelidikan Masalah Bangunan, Bandung.

Anonim. Minimum Design Loads for Buildings and Other Structures, ASCE 7-10 Standard. Amerika

Daniel L. Schodek, (1999), Struktur, Erlangga, Jakarta.

GEOCON Reka Cita (2017) Data tanah Bore Log Lokasi Seram Peaker

http://hmt.mining.itb.ac.id/proyek-35000-mwl, diakses pada hari kamis, 05 April 2018

http://puskim.pu.go.id/peta-zonasi-gempa/

http://puskim.pu.go.id/Aplikasi/desain spektra indones ia 2011/
Harga satuan Jurnal Of Buiding Constraction, Interior \& Material Price Tahun XXIV 2018

Harga Satuan Vendor Gunung Garuda

Johan A, Asjhar I, Septia H. S. (2013). Analisa Tegangan Yang Terjadi Pada Geladak Kapal Tanker Akibat Pengaruh Perubahan Letak Pembujur Geladak Dengan Metode Elemen Hingga. Surabaya

Muhammad,K .(2009). Perencanaan Struktur Baja Pada Bangunan Tujuh Lantai Sebagai Hotel. Surakarta

Mohammad, Y.A.W.(2017). Evaluasi Kinerja Gaya Gempa Terhadap Struktur Gedung Bertingkat Dengan Beton Bertulang Berdasarkan Analisis Respon Spektrum Menggunakan Program Bantu Elemen Hingga. Jakarta 